\title{
Maximum Bite Force following Unilateral Fixed Prosthetic Treatment: A Within-Subject Comparison to the Dentate Side
}

\author{
Bader K. Al-Zarea \\ Department of Prosthetic Dentistry, Faculty of Dentistry, Aljouf University, Sakakah, Saudi Arabia
}

\section{Key Words}

Bite force $\cdot$ Bite gauge $\cdot$ Bite force recording devices $\cdot$ Fixed partial dentures

\begin{abstract}
Objectives: We evaluated the maximum occlusal bite force (MBF) among individuals with fixed partial dentures compared to the opposite dentate side and determined the relationship between MBF and gender, age, and body mass index (BMI). Subjects and Methods: A total of 85 subjects (43 males and 42 females, age range 28-66 years) with fixed partial dentures on one side and dentate on the other side participated in the study. The MBF was measured at the first molar area on both sides using a digital hydraulic bite force gauge. The highest MBF value was recorded from three measurements of bite force at each side (with 45 -second intervals between measurements). Results: The mean MBF was $596.2 \pm 76.3 \mathrm{~N}$ at the dentate side and $580.9 \pm 74.3 \mathrm{~N}$ at the fixed partial denture side. The difference was statistically significant $(p<0.05)$. The MBF values were greater in males as well as in taller and heavier participants. Nevertheless, the $B M I$ had no relationship with MBF values $(p>0.05)$. Conclusions: Within the same subjects, the measured MBF values at the dentate side were higher than those at the fixed partial
\end{abstract}

denture side. Females, lighter, and shorter participants had lower MBF values. Meanwhile, the BMI had no significant relationship to MBF values.

\section{Introduction}

Bite force is an important element of human masticatory function. Assessing bite force facilitates the assessment of masticatory muscle function under clinical and experimental conditions. Various techniques and devices are utilized to evaluate bite force, including portable hydraulic pressure gauges [1], the bite fork [2], force sensing resistors [3], strain gauge transducers [4], pressurized rubber tube [5], foil transducers [6], pressure-sensitive sheets [7], and the gnathodynamometer [8].

Wide variations in bite force values were recorded among different populations $[1,9,10]$. The bite force measured in rural populations was higher than that measured in urban populations [9]. For example, a mean bite force of about 1,500 $\mathrm{N}$ was reported in Eskimos [9], while bite force values of 600-750 N were reported in Western populations [10]. These differences in bite force values could be the result of variations in individual- or tech-

\begin{tabular}{ll}
\hline KARGER 125\% & $\begin{array}{l}\text { (1) 2015 S. Karger AG, Basel } \\
\text { 1011-7571/15/0242-0142\$39.50/0 Openger }\end{array}$ \\
$\begin{array}{l}\text { E-Mail karger@karger.com } \\
\text { www.karger.com/mpp }\end{array}$ & $\begin{array}{l}\text { This is an Open Access article licensed under the terms of the } \\
\text { Creative Commons Attribution-NonCommercial 3.0 Un- } \\
\text { ported license (CC BY-NC) (www.karger.com/OA-license), } \\
\text { applicable to the online version of the article only. Distribu- } \\
\text { tion permitted for non-commercial purposes only. }\end{array}$
\end{tabular}

Dr. Bader K. Al-Zarea

Department of Prosthetic Dentistry, Faculty of Dentistry, Aljouf University King Abdelaziz Street

Sakakah 42421 (Saudi Arabia)

E-Mail baderalzarea@ hotmail.com 
nique-related issues. The latter include interocclusal distance, measuring point on dentition, hardness of biting surface [11], and head position during measurement [1]. Meanwhile, individual-related issues incorporate participants' craniofacial morphology and physical features. Higher bite force values have been reported in long-faced than in short-faced adults $[1,6,12,13]$. Also, increased bite force values with increasing age, height, weight, and body mass index (BMI) $[1,14]$ have been reported. However, Braun et al. [5] have reported low correlation between bite force and body variables. Furthermore, males were found to have higher bite force values than females $[1,2,15-17]$.

Individuals' dental status might influence bite force values. Fully dentate individuals were suggested to have higher bite force values than individuals with complete dentures, removable partial dentures or fixed partial dentures $[18,19]$. Also, individuals with implant-supported overdentures had higher bite force values than individuals with root-retained overdentures or complete dentures [19].

The literature lacks studies that compare bite force values of fixed partial dentures to natural dentition within the same subjects. Hence, the objective of this study was to assess the maximum occlusal bite force (MBF) among patients with fitted fixed partial dentures compared to the opposite dentate side and to determine the associations between MBF and gender, age, and BMI.

\section{Subjects and Methods}

A total of 85 participants (43 males and 42 females) who attended the Prosthodontic Clinics, Aljouf University, Sakakah, Saudi Arabia, were recruited for this study. The study was approved by the Research Committee for Human Studies of Aljouf University. Patients' written informed consent was obtained before the beginning of the study.

Participants were included if they had unilateral fixed partial dentures that replaced the missing second premolar or first molar in one jaw and natural dentition at the opposite side. The prosthesis had to be successfully functioning for $\geq 3$ months, and the participants should have had no complaints, pain or discomfort at the time of assessment. Having the prosthesis successfully functioning for $\geq 3$ months before being enrolled in the study allowed the patients to use it effectively and potentially compensate for the period of having avoided chewing on the side of the missing teeth.

Also, the participants should have no signs or symptoms of temporomandibular disorder, no systemic disease that might affect participants' neuromuscular system (such as Parkinson's disease), and no posterior teeth cross-bite, and they should have a class 1 facial profile and normal facial height and should never have had orthodontic treatment. In addition, the natural molars at the dentate side as well as the opposite prosthesis should show no signs

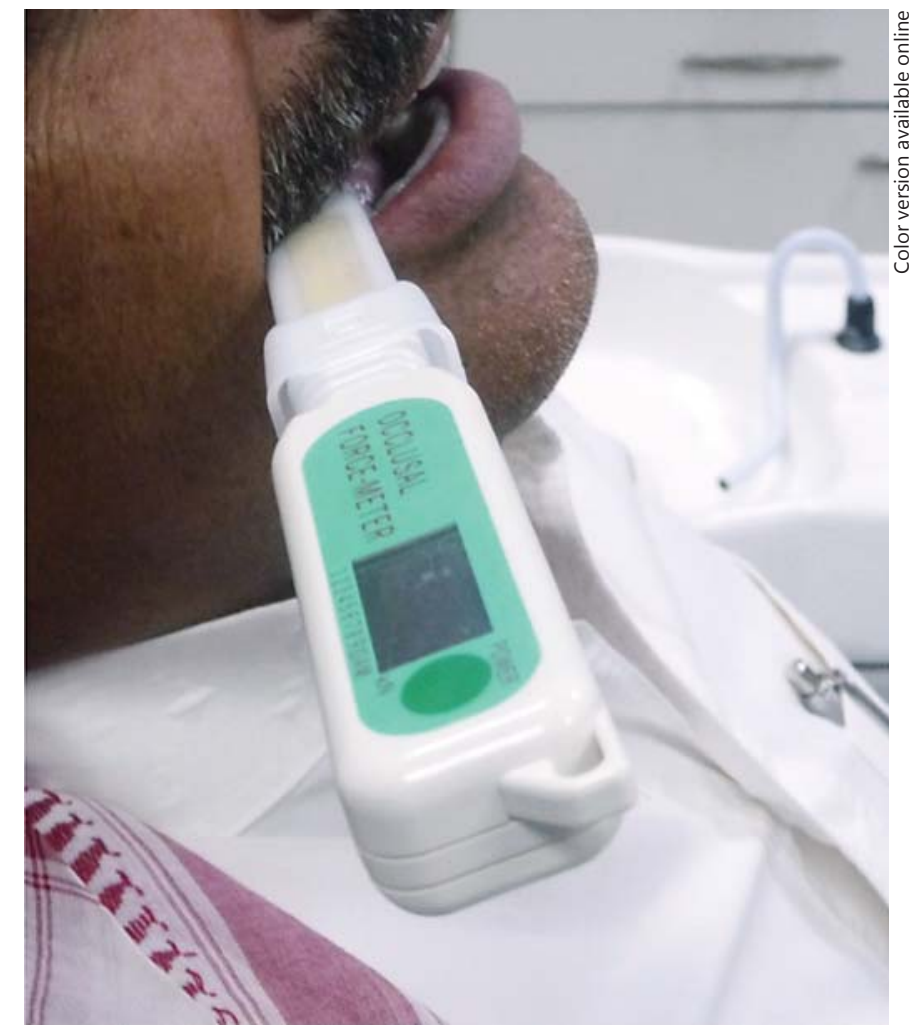

Fig. 1. Measuring bite force using a force transducer occlusal force meter (GM10; Nagano Keiki).

or symptoms if they had been treated, should not have large fillings or carious cavities, and should not have grade $>1$ mobility (periotest value $>19$ ) assessed by Periotest ${ }^{\circledR}$ (Siemens, Bensheim, Germany). Also, the natural molars at the dentate side as well as the opposite prosthesis should not have root canal treatment to prevent their fracture during bite force measurement.

Previous studies reported that $80 \%$ of the total bite force is dispensed at the molar region [20]. Therefore, in the present research, $\mathrm{MBF}$ was measured at the first permanent molar, and the participants were recruited following strict inclusion standards. Gender, age, height, and weight were recorded for each participant. Participants' age ranged from 28 to 66 years. All fixed partial dentures were evaluated following the criteria used by Al-Omiri et al. [21, 22]. In this study, all the recruited participants had a successfully functioning prosthesis throughout the study and no participant was excluded due to prosthetic reasons. The fixed partial dentures were made of ceramometal materials: nickel chromium alloy (Remanium GSoft; Dentaurum, J.P. Winkelstroeter KG, Ispringen, Germany) and Vita porcelain (Vita Zahnfabrik, Bad Säckingen, Germany).

Bite force was measured bilaterally at the first molar region using a force transducer occlusal force meter (GM10; Nagano Keiki, Tokyo, Japan; fig. 1) that consisted of a digital hydraulic pressure gauge and a vinyl biting element covered with plastic sheath. The pressure gauge displayed the bite force values in newtons on its small digital screen. The precision of this force gauge has been previously verified [23]. 
Table 1. Distribution of mean height, weight, BMI, and bite force at both dentate and fixed partial denture sides among the study population according to gender

\begin{tabular}{|c|c|c|c|}
\hline Variables & $\begin{array}{l}\text { All participants } \\
(\mathrm{n}=85)\end{array}$ & $\begin{array}{l}\text { Males } \\
(n=43)\end{array}$ & $\begin{array}{l}\text { Females } \\
(n=42)\end{array}$ \\
\hline Weight, kg & $75.6 \pm 11.0$ & $79.8 \pm 12.0$ & $71.3 \pm 6.6$ \\
\hline Height, $\mathrm{cm}$ & $165.9 \pm 7.0$ & $170.9 \pm 4.2$ & $161.0 \pm 3.7$ \\
\hline BMI & $27.4 \pm 3.0$ & $27.2 \pm 3.6$ & $27.6 \pm 2.3$ \\
\hline \multicolumn{4}{|l|}{ Bite force, $\mathrm{N}$} \\
\hline Dentate side & $596.2 \pm 76.3$ & $649.6 \pm 50.0$ & $539.4 \pm 55.3$ \\
\hline Fixed partial denture side & $580.9 \pm 74.3$ & $633.4 \pm 56.8$ & $527.3 \pm 46.5$ \\
\hline
\end{tabular}

The digital hydraulic pressure gauge has an 8.6-mm-thick bite part with a disposable plastic cover to allow cross-infection control, and it does not interfere with the tongue. However, the plastic cover is fairly rigid to bite, which might potentially cause tooth damage, and this hazard was avoided by excluding participants with heavily restored, cavitated, or root-filled molars.

The force transducer was located on the occlusal surface of the artificial first molar to assess the bite force at the side of the prosthesis. Also, it was located on the mandibular natural first molar to assess the bite force at the dentate side. All participants were in an upright position in the dental chair while measuring the bite force. After that, each participant was asked to bite as heavy as they could on the bite gauge at the prosthesis side and were then asked to relax for $45 \mathrm{~s}$ before biting again on the bite gauge at the dentate side. The whole process was repeated three times for each participant, with 45-second intervals, and the highest value of the bite force $(\mathrm{MBF})$ was recorded for each side.

\section{Method Error}

Method errors for numerical variables in this study were tested using the Dahlberg [24] and Houston [25] formulas and coefficients of reliability. The error ranged between 0.1 and $0.17 \%$ and the coefficient of reliability was above $92 \%$ for all the measurements, representing adequate agreement.

The bite force assessment and clinical examination were performed by B.K.A.-Z. Intraexaminer reliability was verified by intraclass correlation coefficient statistics after the bite force values of 15 participants had been reexamined and remeasured by the same investigator (B.K.A.-Z.) after 1 week, and the intraclass correlation coefficient value was $0.97(\mathrm{p}=0.000)$. Interexaminer reliability was also assessed after the bite force values of the 15 participants had been reexamined and remeasured by another investigator (Prof. Mahmoud AL-Omiri) after 1 week, and the intraclass correlation coefficient value was $0.95(\mathrm{p}=0.000)$. The above tests showed high inter- and intraexaminer reliability.

\section{Statistical Analysis}

The data were collected and then analyzed using SPSS software (version 19.0;, SPSS Inc., Chicago, Ill., USA). Descriptive data were tabulated, and the tested variables were normally distributed. Pearson's correlation test was used to correlate different variables with $\mathrm{MBF}$. Differences in MBF values between the fixed partial denture side and the dentate side were tested using the paired two-sample $t$ test. $p$ value was set at $\leq 0.05$ to indicate significant relationships between variables.

\section{Results}

The participants' mean age was $43 \pm 9$ years. Their mean height was $165.9 \pm 7.0 \mathrm{~cm}$ (range 154-182), their mean weight was $75.6 \pm 11.0 \mathrm{~kg}$ (range 61-100), and the mean BMI was $27.4 \pm 3.0$ (range 21-35). The distribution of mean height, weight, BMI and bite force at both dentate and fixed partial denture sides among the study population according to gender is shown in table 1.

The MBF at the fixed partial denture side was $580.9 \pm$ 74.3 $\mathrm{N}$ (range 401-815). The average MBF was $633.4 \pm$ $56.8 \mathrm{~N}$ for males and $527.3 \pm 46.5 \mathrm{~N}$ for females (table 1 ). Males reported a higher MBF at the fixed partial denture side than females did, and the difference was statistically significant $(\mathrm{p}<0.001)$.

On the other hand, the MBF at the dentate side was $596.2 \pm 76.3 \mathrm{~N}$ (range 433-825). The average MBF was $649.6 \pm 50.0 \mathrm{~N}$ for males and $539.4 \pm 55.3 \mathrm{~N}$ for females (table 1). Males reported a higher MBF at the dentate side than females did, and the difference was statistically significant $(\mathrm{p}<0.001)$.

At the fixed partial denture side, patients with a higher BMI had a higher MBF $(\mathrm{p}<0.001)$. In addition, at the dentate side, patients with a higher BMI also reported a higher $\operatorname{MBF}(\mathrm{p}=0.003)$.

Using $t$ test statistics, the maximum bite force (MBF) at the dentate side was found to be higher than the MBF at the fixed partial denture side $(\mathrm{p}=0.001)$. A multiple linear regression analysis showed that gender and BMI were able to predict the bite force for both treated sides $\left(\mathrm{p}<0.001 ; \mathrm{R}^{2}=0.563\right.$ and 0.226 , respectively). Also, gender and BMI were able to predict the bite force for the dentate side $\left(\mathrm{p}<0.001 ; \mathrm{R}^{2}=0.583\right.$ and 0.179 , respectively).

\section{Discussion}

The current study demonstrated that the MBF values at the dentate sides were significantly different from those at the fixed partial denture prosthesis. The MBF of $596.2 \mathrm{~N}$ measured at the dentate side was within the wide range $(213-1,500 \mathrm{~N})$ reported previously $[1,2,4,15,18$, $22,26,27]$. The wide range could be due to the use of different devices with diverse biting elements for MBF measurement $[1,7,27]$. The accuracy and precision of bite force measurements might be influenced by the mechanical features of the used bite force measuring system. In addition, populations from different racial backgrounds could have different bite forces as a result of different eat- 
ing habits, body features, and life styles. The MBF measured at the dentate side is in agreement with the results of Al-Omiri et al. [22], and this could be due to the use of a similar study design for participants from similar backgrounds.

The MBF of $581 \mathrm{~N}$ measured at the fixed partial denture side was less than that measured at the dentate side in the same patients. Nevertheless, this value is higher than what has been reported in previous studies on complete dentures, overdentures supported by implants, partial dentures, or fixed partial dentures $[18,19,28]$. This difference could be attributed to the fact that previous investigations assessed different types of prosthesis or used other patients as controls, while in the current study, a within-subject study design was applied and the other side of the jaw of the same patients was used as control. In this study, the measured MBF values at the treated side are in agreement with the MBF values reported by Al-Omiri et al. [22]. This could be due to the use of a similar study design for participants from similar backgrounds. However, Al-Omiri et al. [22] used fixed implant-supported prostheses, whereas in this study, fixed tooth-supported prostheses were investigated. It is interesting that bite force values at sides with fixed prostheses were similar in both studies. Having different support did not affect the value of measured MBF. This could be due to the fact that natural dentition was opposite the prosthesis side in both studies. Similar study designs, measuring tools, and participants' backgrounds could also explain this finding.

Although bite force values were statistically different between dentate and treated sides, the difference ranged from 10 to $32 \mathrm{~N}$. This difference might be considered clinically unimportant because the bite force at both sides is more than what is required for sufficient mastication and chewing in humans $[1,9,10,14]$. Consequently, a fixed partial denture treatment modality can improve bite force and chewing efficiency and therefore could potentially improve patients' satisfaction.

Males reported higher MBF values than females did in the present research, which is similar to previous studies $[1,2,11-14,16,17]$. This could be attributed to the fact that males have a larger dental size than females, which corresponds to larger periodontal ligament areas and thus might produce higher MBF values. Another explanation could be the larger muscular body features of males, which might result from the anatomic variations between the genders [15]. In comparison to females, type 2 muscle fibers with a larger diameter and a greater sectional area constitute the masseter muscles of males [28].
The present investigation demonstrated a significant relationship between BMI and MBF. A potential reason for this could be the consequences of physical workout in adults due to work or sport [2]. However, this finding is in contrast with the results of other studies $[1,4,22]$. A probable reason for this difference could be the various designs used in each study. In our study, bite force measurements were carried out following unilateral fixed partial denture prosthetic treatment to facilitate a withinsubject comparison to the opposite dentate side. This study design avoided the potential effects of individual differences between participants and allowed for standardized settings of MBF measurements.

Study limitations include the size of the study sample, the battery voltage and temperature of the hydraulic pressure gauge that could have potential effects on the results, and not measuring the bite force at the treated side before the prosthodontic treatment. It is logical to expect that patients chew more frequently on the dentate side than on the side with missing teeth. Therefore, the detected difference between treated and dentate sides could have been influenced by the chewing side preference $[29,30]$. Also, the potential of jaw flexure as well as variations in muscle tonicity during unilaterally closing down on hard objects might potentially affect the recorded bite force value.

Further studies are needed among different populations and on larger samples to recognize the effects of gender, ethnicity, diet, and other physical characteristics on $\mathrm{MBF}$ values, and investigations are needed to evaluate comparisons of $\mathrm{MBF}$ values produced by various types of tooth-supported conventional prosthetic rehabilitations and different implant-supported prosthetic rehabilitations. Further investigations are also required to evaluate whether chewing side preference is related to bite force values in order to solve the controversy regarding this issue $[29,30]$.

\section{Conclusions}

Within the same subjects, MBF values at the dentate side were higher than those at the fixed partial denture prosthesis side. Although statistically significant, this difference might be clinically unimportant as the bite force values at both sides are adequate for human mastication and chewing. Females and participants with lower BMI had lower MBF values. 


\section{Acknowledgment}

The author would like to thank Aljouf University for supporting this project.

\section{References}

1 Abu Alhaija ES, Al Zo'ubi IA, Al Rousan ME, et al: Maximal occlusal bite forces in Jordanian individuals with different dentofacial vertical skeletal patterns. Eur J Orthod 2010; 32:71-77.

2 Kiliaridis S, Kjellberg H, Wenneberg B, et al: The relationship between maximal bite force, bite force endurance, and facial morphology during growth. A cross-sectional study. Acta Odontol Scand 1993;51:323-331.

3 Fernandes C, Glantz PO, Svensson S, et al: A novel sensor for bite force determinations. Dent Mater 2003;19:118-126.

4 Braun S, Hnat WP, Freudenthaler JW, et al: A study of maximum bite force during growth and development. Angle Orthod 1996;66: 261-264.

5 Braun S, Bantleon HP, Hnat WP, et al: A study of bite force, part 2. Relationship to various cephalometric measurement. Angle Orthod 1995;65:373-377.

6 Proffit WR, Fields HW, Nixon WL: Occlusal forces in normal- and long-face adults. J Dent Res 1983;62:566-570.

7 Sondang P, Kumagai H, Tanaka E, et al: Correlation between maximum bite force and craniofacial morphology of young adults in Indonesia. J Oral Rehabil 2003;30:1109-1117.

8 Ortug G: A new device for measuring mastication force (Gnathodynamometer). Ann Anat 2002;184:393-396.

9 Bonjardim L, Gaviao M, Pereira L, et al: Bite force determination in adolescents with and without temporomandibular dysfunction. J Oral Rehabil 2005;32:577-583.

10 Hagberg C: Assessments of bite force: a review. J Craniomandib Disord 1987;1:162169.

\section{Disclosure Statement}

The authors have no conflicts of interest to declare.
11 Serra CM, Manns AE: Bite force measurements with hard and soft bite surfaces. J Oral Rehabil 2013;40:563-568.

12 Ingervall B, Helkimo E: Masticatory muscle force and facial morphology in man. Arch Oral Biol 1978;23:203-206.

13 Ringqvist M: Isometric bite force and its relation to dimensions of the facial skeleton. Acta Odontol Scand 1973;31:35-42.

14 Shiau YY, Wang JS: The effects of dental condition on hand strength and maximum bite force. Cranio 1993;11:48-54.

15 Waltimo A, Kononen M: Maximal bite force and its association with signs and symptoms of craniomandibular disorders in young Finnish non-patients. Acta Odontol Scand 1995;53:254-258.

16 Bonakdarchian M, Askari N, Askari M: Effect of face form on maximal molar bite force with natural dentition. Arch Oral Biol 2009;54: 201-204.

17 Koç D, Doğan A, Bek B: Effect of gender, facial dimensions, body mass index and type of functional occlusion on bite force. J Appl Oral Sci 2011;19:274-279.

18 Miyaura K, Morita M, Matsuka Y, et al: Rehabilitation of biting abilities in patients with different types of dental prostheses. J Oral Rehabil 2000;27:1073-1076.

19 Fontijn-Tekamp FA, Slagter AP, Van Der Bilt A, et al: Biting and chewing in overdentures, full dentures, and natural dentitions. J Dent Res 2000;79:1519-1524.

20 Shinogaya T, Sodeyama A, Matsumoto M: Bite force and occlusal load distribution in normal complete dentitions of young adults. Eur J Prosthodont Restor Dent 1999;7:65-70.

21 Al-Omiri MK, Abu Hammad O, Lynch E, et al: Impacts of implant treatment on daily living. Int J Oral Maxillofac Implants 2011;26: 877-886.
22 Al-Omiri MK, Sghaireen MG, Alhijawi MM, et al: Maximum bite force following unilateral implant-supported prosthetic treatment: within-subject comparison to opposite dentate side. J Oral Rehabil 2014;41:624-629.

23 Sakaguchi M, Ono N, Turuta H, et al: Development of new handy type occlusal force gauge (in Japanese). Iyodenshi To Seitai Kogaku 1996;34:53-55.

24 Dahlberg G: Statistical Methods for Medical and Biological Students. New York, Inter Science Publications, 1940, pp 122-132.

25 Houston WJB: The analysis of errors in orthodontic measurements. Am J Orthod 1983;83: 382-390.

26 Calderon Pdos S, Kogawa EM, Lauris JR, et al: The influence of gender and bruxism on the human maximum bite force. J Appl Oral Sci 2006; 14:448-453.

27 Bakke M, Holm B, Jensen BL, et al: Unilateral, isometric bite force in 8- to 68-year-old women and men related to occlusal factors. Scand J Dent Res 1990;98:149-158.

28 Haraldson T, Carlsson GE, Ingervall B: Functional state, bite force and postural muscle activity in patients with osseointegrated oral implant bridges. Acta Odontol Scand 1979;37: 195-206.

29 Martinez-Gomis J, Lujan-Climent M, Palau S, et al: Relationship between chewing side preference and handedness and lateral asymmetry of peripheral factors. Arch Oral Biol 2009;54: 101-107.

30 Gomes SG, Custodio W, Faot F, et al: Chewing side, bite force symmetry, and occlusal contact area of subjects with different facial vertical patterns. Braz Oral Res 2011;25:446452 . 